Original Research Article

\title{
Evaluation of teaching methods in pharmacology among MBBS students
}

\author{
Vijay A. Vare ${ }^{1}$, Dnyaneshwar G. Kurle ${ }^{2}$, Tushar R. Bagle ${ }^{1 *}$, Rohan C. Hire ${ }^{1}$, \\ Abhaykumar O. Shukla ${ }^{1}$
}

${ }^{1}$ Department of Pharmacology, RGMC and CSMH, Kalwa, Thane, Maharashtra, India ${ }^{2}$ Department of Pharmacology, Seth GSMC and KEMH, Parel, Mumbai, Maharashtra, India

Received: 15 April 2017 Accepted: 24 April 2017

*Correspondence to:

Dr. Tushar R. Bagle,

Email: tusharbagle21@ gmail.com

Copyright: (C) the author(s), publisher and licensee Medip Academy. This is an openaccess article distributed under the terms of the Creative Commons Attribution NonCommercial License, which permits unrestricted noncommercial use, distribution, and reproduction in any medium, provided the original work is properly cited.

\begin{abstract}
Background: Pharmacology is one of the most important subjects in medical curriculum. It is basis of medical science and the foundation of treatment. The applied aspect forms the basis of clinical rational therapeutics.

Methods: A cross-sectional study among 100 undergraduate medical students was undertaken after Institutional Ethics committee permission. Questionnaire was prepared from previous studies and validated by experts. These were administered to the participants after receiving their due consent.

Results: The mean age of students was $21.31 \pm 2.93$ years. There were $72 \%$ females and $28 \%$ males. The average rating given for Pharmacology subject was $7.95 \pm 1.16$. Females $(8.38 \pm 1.24)$ rated Pharmacology subject more than males (7.51 \pm 1.09 ). 62\% liked combination of LCD and Blackboard for teaching. 34\% felt group discussion was the ideal Teaching learning method for learning Pharmacology. The most interesting topic was General Pharmacology $(31 \%)$ and ANS (45\%) was the most difficult subject to understand. The most important topic in practical's was $25 \%$ prescription writing and least was experimental graphs (2\%). Preferred source to learn Pharmacology was combination of textbook and lecture (42\%). $81 \%$ students liked integrated teaching of pharmacology with other subjects. $93 \%$ felt there should be more use of audiovisual aids, $91 \%$ wanted more of clinical pharmacology and $88 \%$ wanted more of group discussions. $91 \%$ felt calculation of pharmacokinetic parameters is clinically applicable.

Conclusions: There is need to develop innovative teaching learning methods and include more of clinical pharmacology in the undergraduate pharmacology subject.
\end{abstract}

Keywords: Didactic, Lecture, Practical, PowerPoint, Textbook

\section{INTRODUCTION}

Pharmacology is a dynamic subject and one of most evolving branches in medicine. As a subject, included in the second year (III, IV and V semester) of the Bachelor of Medicine and Bachelor of Surgery (MBBS) curriculum in India. It serves as a foundation stone for all the physicians in clinical practice. The subject of Pharmacology embraces pharmacy,experimental and clinical sciences. ${ }^{1}$ In the third semester students are acquainted with patients and they begin to understand clinical aspects of diseases. ${ }^{2}$ Teaching pharmacology during this phase is a challenge. ${ }^{3}$ The objective of pharmacology teaching is to make undergraduate medical students capable to take rational therapeutic decisions in clinical scenarios. $^{2}$

Conventionally in medical schools, pharmacology teaching is lecture centered on acquiring theoretical knowledge about drugs, the medical student is not trained adequately for therapeutic pursuits. ${ }^{4}$ The purpose of teaching pharmacology to medical students is to train them on rational and scientific basis of prescribing medicines in therapeutics. ${ }^{5}$ 
Pharmacology, like any other branch of medical science is a challenging branch. It is ubiquitous subject, required for all medical and surgical faculties. Thus many drugs are added in assemblage of drugs everyday changing the strategies for a given clinical condition. ${ }^{6}$ Due to this, syllabus content is overburden, and students find hard to remember and recall concepts and drug names. Thus there is need of reforms in undergraduate teaching and this can be done by reviewing teaching program and its methodologies at regular intervals. ${ }^{7}$

A curriculum is a vision, a road map to meet the academic objectives. The undergraduate medical curriculum in Pharmacology subject has been a topic of debate, there is an opinion that teaching pharmacology in medical schools has lost track with the rapid changes in medical practice. Thus it is necessity to make pharmacology teaching more interesting and applicable..$^{5,8}$

Teaching is considered as ever evolving processes especially in medical school. Consequently it needs to be upgraded continuously. Major hurdle for any medical school is to deliver enormous amount of knowledge in narrow schedule and students are expected to retain, remember and effectively interpret. ${ }^{9}$ Today, the teaching of pharmacology has become theoretical based with trivial clinical application. ${ }^{10}$

The pharmacology lectures can be made more interesting, understanding and relevant by reviewing the teaching program at periodic intervals. ${ }^{6}$ Teacher can adapt new methods of providing basic knowledge about drugs and drug therapies if they know the learning styles of students. Thus the study was taken to determine the current needs of undergraduate medical students in learning pharmacology.

\section{METHODS}

This was a cross-sectional questionnaire based study of 100 undergraduate medical students (50 from Fifth term completed and 50 from Sixth term students) in medical college and tertiary care Hospital.

The questionnaire was prepared from previous studies review of literature and previous studies by Rani, Manjunath, Sawhney, Abdulghani, Jai Krishna, Agarwal and Chavda. ${ }^{1,7,11-15}$ The validity (content and criterion) of the questionnaire was evaluated by three teachers, two from department of pharmacology and one from medical education unit of college.

The questionnaire consisted of two parts, in first part demographic information of the students was noted and in the second part information related to pharmacology teaching learning methods and opinion about pharmacology teaching was administered. Study duration was from 19 September 2016 to 10 March 2017. Study site was department of Pharmacology and Therapeutics.
A pilot study was conducted on 12 students and modifications were made in the questionnaire. Test retest reliability was estimated with 15 students by taking two interviews seven days apart and this were not included in the final analysis. Internal consistency reliability by Cronbach's alfa coefficient was 0.86. Participation was voluntary and students willing to give informed consent were enrolled in study. The objectives of the study were explained to the participants. Demographic information statement and Questionnaire were administered and collected after 20-40 minutes. A written informed consent was obtained from each participant. Students age $\geq 18$ years and willing to give informed consent were included. The exclusion criteria were students not willing to participate or returning incompletely filled forms. Total 116 questionnaires were distributed, 112 were collected out of which 100 were selected based on inclusion and exclusion criteria. The identity and data in the present study was kept confidential.

Statistical analysis: Data was expressed as mean \pm standard deviation, frequency and percentage. $\mathrm{P}$ value $<0.05$ was considered to be statistically significant. Chi square test was used to test the association of different variables. Parametric tests (Student's t-test) was used to compare the scores among subgroups of medical students. Statistical analysis was done using GraphPad Prism version 5.0 software for Windows, San Diego.

\section{RESULTS}

There were total 100 students, 72 were females (F) and 28 were males $(\mathrm{M}) .85$ were from urban area and 15 from rural area of residence. 74 from English medium, 21 were from Marathi and 5 from Hindi medium of education. 19 students parents were from medical and 81 students parents from nonmedical background. The average age of the participants was $21.31 \pm 2.93$ years (range 18 to 26). 45 students felt pharmacology is very important, 40 important $(\mathrm{F}=62, \mathrm{M}=23), 10$ were neutral and 5 felt subject is not important $(\mathrm{F}=10, \mathrm{M}=05)$, both males and females felt subject is equally important, there was no statistically significant difference $(\mathrm{P}=0.75)$. The average rating given for Pharmacology subject was $7.95 \pm 1.16$, males (7.51 \pm 1.09$)$ and females $(8.38 \pm 1.24)$, the rating was statistically significant for females compared to males $(\mathrm{p}=0.0016)$. The average ratings given by students of parents from medical field was $8.45 \pm 1.18$ and significant $(\mathrm{p}=0.005)$ as compared from nonmedical field $7.43 \pm 1.12$.

The ideal medium by undergraduate students for learning Pharmacology was combination of Liquid Crystal Display (LCD) and Blackboard (62) $(\mathrm{F}=50, \mathrm{M}=12)$, followed by LCD 19, 17 liked black board only, while 2 liked overhead projector $(\mathrm{F}=22, \mathrm{M}=16)$. Female students felt LCD and blackboard method is more effective that males $\quad(p=0.021)$. The ideal teaching learning methodology for learning Pharmacology by undergraduate students was group discussion (34), 
followed by didactic lectures (27), tutorial (23), demonstration (13) and seminars (3).

\section{Table 1: Students opinion about pharmacology subject.}

\begin{tabular}{|c|c|c|c|}
\hline Opinion & Agree & Neutral & Disagree \\
\hline $\begin{array}{l}\text { I find pharmacology } \\
\text { lecturers interesting } \\
\text { and stimulating }\end{array}$ & 79 & 0 & 21 \\
\hline $\begin{array}{l}\text { Pharmacology is my } \\
\text { favorite subject in } \\
\text { 2ndyear of MBBS }\end{array}$ & 63 & 18 & 19 \\
\hline $\begin{array}{l}\text { The Pharmacology } \\
\text { subject has helped me } \\
\text { to develop my } \\
\text { therapeutic rationale } \\
\text { reasoning skills }\end{array}$ & 53 & 35 & 12 \\
\hline $\begin{array}{l}\text { I would like more of } \\
\text { problems stimulated } \\
\text { learning (PSL) in } \\
\text { Pharmacology }\end{array}$ & 72 & 10 & 18 \\
\hline $\begin{array}{l}\text { The subject will help } \\
\text { me immensely in } \\
\text { choosing drugs } \\
\text { rationally in my future } \\
\text { clinical practice }\end{array}$ & 84 & 5 & 11 \\
\hline $\begin{array}{l}\text { I have come across } \\
\text { various dosage forms } \\
\text { in clinical postings and } \\
\text { has helped me in better } \\
\text { understanding of the } \\
\text { subject }\end{array}$ & 83 & 0 & 17 \\
\hline $\begin{array}{l}\text { Mechanism of action of } \\
\text { drugs can be better } \\
\text { understand with help of } \\
\text { charts }\end{array}$ & 76 & 11 & 13 \\
\hline $\begin{array}{l}\text { Calculation of } \\
\text { pharmacokinetic } \\
\text { parameters (e.g. Vd, } \\
\text { t1/2, Therapeutic } \\
\text { index) is relevant and is } \\
\text { clinically applicable. }\end{array}$ & 91 & 0 & 9 \\
\hline $\begin{array}{l}\text { Pharmacovigilance } \\
\text { cases in practical } \\
\text { pharmacology has } \\
\text { helped in better } \\
\text { understanding of ADRs } \\
\text { and ensures safety of } \\
\text { the drugs }\end{array}$ & 86 & 9 & 5 \\
\hline $\begin{array}{l}\text { I would like to include } \\
\text { recent advances in } \\
\text { Pharmacology } \\
\text { curriculum }\end{array}$ & 67 & 21 & 12 \\
\hline $\begin{array}{l}\text { I would like MCQs to } \\
\text { be continued to be } \\
\text { included in the } \\
\text { assessment }\end{array}$ & 91 & 3 & 6 \\
\hline
\end{tabular}

Table 2: Opinion about changes recommended in pharmacology teaching.

\begin{tabular}{|lll|}
\hline Opinion & Yes & No \\
\hline Audio-visual support should be increased & 93 & 7 \\
\hline $\begin{array}{l}\text { Clinical pharmacology cases of different } \\
\text { varieties should be introduced }\end{array}$ & 91 & 9 \\
\hline $\begin{array}{l}\text { Group discussions should be introduced in } \\
\text { therapeutics }\end{array}$ & 88 & 12 \\
\hline $\begin{array}{l}\text { Case based learning should be increased } \\
\text { Case Presentations should be increased }\end{array}$ & 63 & 17 \\
\hline $\begin{array}{l}\text { Number of Pharmacology lectures should } \\
\text { be increased }\end{array}$ & 57 & 43 \\
\hline Student seminars should be increased & 11 & 89 \\
\hline
\end{tabular}

The most Interesting topic according to students in Pharmacology was General Pharmacology (31), followed by 24 for Cardio Vascular System (CVS), Autonomic Nervous System (ANS) for 18, Central Nervous System (CNS) for 16, 5 Endocrine, 2 Gastrointestinal System (GIT) and 4 were other topics. The most difficult system to understand in Pharmacology was ANS 45\%, 39 CNS, 11 CVS, 2 Endocrine, 2 Chemotherapy, Antimicrobials 1.

The most important topic in practical pharmacology according to undergraduate medical students was 25 for prescription writing, followed by therapeutic rationale by 21 , pharmacodynamics by 16 , pharmacokinetics 15 , case presentation 13, Adverse drug reaction (ADR) 8 and experimental graphs 2. Source to learn Pharmacology was 42 preferred combination of textbook and lecture, 26 preferred text book, 24 for combination of lecture and internet and 8 for internet only. 81 students liked integrated teaching of Pharmacology with other subjects while 19 did not liked integrated teaching. Study pattern followed by students to learn pharmacology was to read during term exams 39, followed by 31 for tutorial, 15 regularly by interest, 13 for gaining knowledge and 2 for final exams.

\section{DISCUSSION}

Pharmacology is subject of epochal in medical curriculum and its applied aspects are the base of rational Therapeutics. The clinical pharmacology exercises sensitize students for rational use of medicines, but these skills are minimally reinforced during clinical posting and so their practical application remains incomplete. ${ }^{16}$

In our study there were 72 females and average age was 21.31 years and $19 \%$ parents from medical profession. The average rating given was more by females and from students whose parents were from medical profession. Sudy by Sekhri had $85 \%$ females and mean age was $19.6 \pm 0.87$ years. ${ }^{17}$ Study by Abdulghani had $24.7 \%$ Males, $75.3 \%$ females and $11.3 \%$ fathers, $4.70 \%$ mothers were from medical field while study by Jai krishna had $65 \%$ parents from nonmedical professionals. ${ }^{12,13}$ The number of students, gender distribution and parents profession in our study match with other studies. 
In our study $52 \%$ felt group discussion and $21 \%$ felt didactic lectures were ideal teaching method. Study by Padmanabha had $98.38 \%$ students that liked clinical cases, $90.32 \%$ group discussion as it improves understanding. ${ }^{16}$ Study by Zaman had $50 \%$ students that liked clinically oriented and $25 \%$ liked didactic lectures. ${ }^{18}$ Study by Abdulghani had $43.3 \%$ students that agreed clinical sessions and objectively structured practical examination (OSPE) stimulated learning more than didactic lectures. ${ }^{12}$ Thus students feel group discussions and didactic lectures are ideal teaching methods.

In the current study $62 \%$ students preferred combination of LCD projector and blackboard. Study by Manjunath had $81 \%$ students that felt combination of LCD projector and blackboard ideal teaching media. ${ }^{7}$ Study by Bandopadhyay had $45.98 \%$ students that agreed and $50.57 \%$ strongly agreed that power point presentation and chalk\& talk as combined, was the best teaching-learning method. ${ }^{19}$ Similarly study by Amane had 90\%, Padmanabha had $59.68 \%$ students that liked combination of blackboard and PowerPoint presentations. ${ }^{6,16}$ Study by Desa showed that chalkboard method obtained significantly higher score in MCQ (Multiple Choice Questions) test than power point while study by Seth had majority students that preferred PowerPoint presentations. ${ }^{20,21}$ Our study and other studies has preferred ideal teaching methodology is combination of powerpoint and blackboard.

In our study the most interesting topic was General Pharmacology followed by CNS while ANS was the most difficult system to understand. Study by Tabish found $41.91 \%$ interested in General Pharmacology, $13.19 \%$ in CVS, $12.31 \%$ are interested in CNS while $22.46 \%$ felt all the topics in pharmacology are interesting. ${ }^{2}$ In study by Bhosale students liked Endocrinology (53.2\%) topic followed by CVS (48.4\%) and General pharmacology $(37.8 \%) .{ }^{22}$ Similarly studies by Zaman had CVS (34\%) and Prasad had CNS $(60 \%)$ as most interesting topic. ${ }^{18,23}$ Study by Manjunath found most difficult system to understand was ANS (53.12\%) and CVS (20.31\%). ${ }^{7}$ while study by Rani noticed $23 \%$ GIT, $19.6 \%$ found Endocrinology interesting and General Pharmacology (3.8\%) least interesting. ${ }^{1}$ Thus there are various topics of interest and disinterest in Pharmacology, it is important to look Pharmacology as a whole subject and accordingly to distribute topics as important and desirable to know.

In our study prescription writing was most important and experimental graphs the least important topic. Study by Rani found prescription writing $(33.5 \%)$, criticism of prescription (27.8\%) and clinical problems (26.7\%) interesting and least interesting were experimental graphs $(5.6 \%) .{ }^{1}$ Study by Bhosale had prescription writing (64.9\%), comments on fixed dose combinations $(46.7 \%)$ were found most interesting. ${ }^{22}$ Study by Prasad had $57 \%$ students that felt clinical exercises interesting, fixed dose combination $(40 \%)$ and experimental graphs $(11 \%){ }^{23}$ Study by Manjunath had $67 \%$ of students felt that calculation of pharmacokinetic parameters and $95 \%$ students felt Pharmacovigilance problems in practicals were relevant and helped them in better understanding of ADRs. $^{7}$ Thus there is need to refine practical pharmacology and make them most interesting to utilize knowledge in solving clinical problems.

In our study $42 \%$ preferred combination of textbook and lecture as source to learn pharmacology. Study by Rani had $46.2 \%$, by Zaman (37\%) and Prasad had (56\%) students that preferred text book and lectures to study Pharmacology. ${ }^{1,18,23}$ Jaikrishna study had $76.56 \%$ students that felt pharmacology lectures stimulating while $28.12 \%$ believed it as their favourite subject. ${ }^{13}$ Till date students heavily depend on lectures and textbooks for learning Pharmacology that are still an important source of information for learning Pharmacology.

In the present study, 39\% learned pharmacology for term exams. Study by Zaman had $47 \%$ students studied during examinations, $24 \%$ for regular tests, $11 \%$ to gain knowledge and $10 \%$ because of interest. ${ }^{18}$ Study by Rani had $56.58 \%$ that studied during exams. ${ }^{1}$ Similar results by Prasad and Study by Tabish had $37.36 \%$ students learned for gaining more knowledge, $23.33 \%$ because of interest, $32.97 \%$ because of tutorials whereas $1.46 \%$ studied for final exams. ${ }^{2,23}$ Thus there is need to make teaching of Pharmacology interesting so that students read it regularly.

In our study students wanted more group discussions, audiovisual aids, case based learning, and fewer seminars. Study by Rani had $25.5 \%$ of students that felt of including recent advances in Pharmacology. 29.5\% of students found Clinical Pharmacology interesting method, followed by tutorials (18\%) audiovisual aided lecture $(14 \%)$ while the least interesting was student's seminars $(3.5 \%) .{ }^{1}$ Study by Manjunath had $82 \%$ students that wanted group discussions, $98.43 \%$ wanted case based learning, $70 \%$ wanted recent advance in curriculum while $80 \%$ were in favour of MCQs in assessment of their academic performance. ${ }^{7}$ Garg A et al study showed that students $(35 \%)$ were not in favor of giving seminars. ${ }^{24}$ Study by Padmanabha had $69.35 \%$ agree to have seminars. ${ }^{16}$ According to Jai Krishna (37.66\%) students wanted to make more use of audio-visual aids, $31.17 \%$ wanted group discussions, while $19.48 \%$ wanted decrease in number of lectures. ${ }^{13}$ Study by Badyal, students were satisfied with interactive teaching methods for teaching undergraduate medical students that include tutorials, demonstrations, experimental exercises etc. ${ }^{25}$ Lecture delivery has impact on students understanding and retention of concept. ${ }^{2}$

In our study $81 \%$ liked integrated teaching of Pharmacology subject with other subjects. Study by Manjunath $89.06 \%$ and Jaikrishna had $65 \%$ students wanted pharmacology more closely integrated with clinical sciences. ${ }^{7,13} 45.42 \%$ students wanted integrated teaching to be implemented..$^{2}$ An integrated approach can 
have learner centered curriculum that can develop competencies required for todays physician.

Traditionally, Pharmacology has focused more on factual information with little emphasis on clinical and applied aspects. Pharmacy and experimental practical's have still remained foundation of practical pharmacology. The utilization and importance of practical exercises have been the center of academic debate. ${ }^{8}$ It is important that modifying teaching methodologies at timely intervals has become a necessity. Feedbacks enhance learning and provide an opportunity to assess the lacunae in current system. ${ }^{1,16}$

In Malaysia, pharmacology learning has transformed from laboratory teaching to bedside patient approach. ${ }^{26}$ While at McMaster University in Canada the problem based learning curriculum is integrated across organ systems, population and behavior. ${ }^{27}$ The purpose of pharmacology is student are expected to develop skills that will help them in clinical postings and throughout their medical profession. In undergraduate teaching animal experiments can be demonstrated by Computer Aided Education. according to 2009 MCI amendment. Computer Assisted Learning (CAL) is helpful in teaching pharmacology by simulating action of drugs on receptors and animal tissues. ${ }^{28,29}$

Three visual mode of teaching such as power-point, small group graphical illustration and computer assisted exercises complement learning. Didactic lectures need to be complemented with visual aids and other forms to facilitate learning. ${ }^{3}$ Problem based learning and OSCE need to be introduced to students. ${ }^{1}$ E-Learning is still at infancy in Indian medical curriculum. Introduction of Elearning and CAL provides an opportunity to modify and make teaching easy. ${ }^{30}$

Modification focuses on processes, approaches and not only on contents. These can be in form of active learning such as thinkpair share, minute papers, concept understanding by use of models, CAL and working on mannequins that can be incorporated. 20,31 This modification can be achieved by bring about horizontal and vertical integration in pharmacology. ${ }^{31}$

Thus there is need to develop innovative teaching learning modules, which can foster more of interaction between teachers and students, better communication among students thus creating significant learning environments to improve the quality of future medical practitioners.

\section{ACKNOWLEDGMENTS}

Authors would like to thank Dean Dr. C. Maitra and Dr. Kartikeyan, Prof and Head, P.S.M Department for their support.
Funding: No funding sources

Conflict of interest: None declared

Ethical approval: The study was approved by the Institutional Ethics Committee (IEC number: RGMC/CSMH/IEC/9/02/2016)

\section{REFERENCES}

1. Rani V, Tekulapally K, Padmavathi V, Simpson GB. Second year Medical students perception about pharmacology and teaching methodologies used: A questionnaire based cross sectional study. Indian Journal of Basic and Applied Medical Research. 2016;5(4):238-45.

2. Tabish A, Sharma S, Syed AS, Sharma R, Mahendra J. Assessment of Effectiveness of Different Teaching Methodologies in Pharmacology for Undergraduates at a Rural Medical College of Bastar Region. International Journal of Biomedical Research. 2015;6(07):512-7.

3. Sagaran JV, Indla R, Roy R, Srinivasamurthy S, Kuruvilla A. Comparative evaluation of the effects of visual aids on learning pharmacology of autonomic nervous system. Journal of Contemporary Medical Education. 2015;3(4):188-90.

4. Abdulghani MA. Medical Students' Feedback about Teaching Fundamental Pharmacology in an Integrated Curriculum. British Journal of Education, Society \& Behavioural Science. 2016;15(3):1-7.

5. Parimala K, Subash KR, Jagan N, Vijay Kumar S, Viswanathan S, Chandrasekhar M. Assessment of Pharmacology Teaching - A Critical Appraisal by Medical School Learners. International Journal of Medical Research and Health Sciences. 2013;2(2):124-9.

6. Amane HS, Kaore SN, Vasvani SV. Evaluation of Existing Teaching Methods Used for Lecture Classes In Pharmacology. Int $\mathrm{J}$ Pharm Bio Sci. 2013;4(1):193-8.

7. Manjunath SM, Nagesh RG, Srinivas TR, Someswara GM. A study on the evaluation of medical students' perception. and feedback of teaching-learning of pharmacology in a medical college. International Archives of Integrated Medicine. 2015;2(9):102-10.

8. Desai M. Changing face of pharmacology practicals for medical undergraduates. Indian J Pharmacology. 2009;41:151-2.

9. Josh A, Ganjiwale J. Evaluation of Students' Perceptions Towards an Innovative TeachingLearning Method During Pharyymacology Revision Classes: Autobiography of Drugs. Journal of Clinical and Diagnostic Research. 2015;9(7):01-4.

10. Ruckmani A. The role of pharmacologists: Present and future (report). Indian Journal Pharmacology. 2006;38(2):145-6.

11. Sawhney V, Bhat MY, Farhat S. A questionnaire based study of Pharmacology curriculum in undergraduate students. International Journal of Research in Pharmacology and Pharmacotherapeutics. 2014;3(4):382-6. 
12. Abdulghani MAM, Al-Naggar RA. Students' perceptions about learning pharmacology at a single private institute in Malaysia. Journal of Taibah University Medical Sciences. 2015;10(1):40-4.

13. Jai Krishna, Singh A, Goel S, Gupta A, Sharma P, Mirza RUB, et al. Students current perceptions and feedback on teaching and learning Pharmacology from an evolving medical school. IAIM. 2015;2(7):99-104.

14. Agarwal R, Ismail NF. Students Perception of Teaching Methods in Pharmacology in a Malaysian Medical School. Journal of Clinical And Health Sciences. 2016;1(1):16-21.

15. Chavda N, Yadav P, Chaudhari M, Kantharia N. Second year student's feedback on teaching methodology and evaluation methods in pharmacology. Nation J Physiol Pharm Pharmacol. 2011;1:23-31.

16. Padmanabha TS, Manu G, Kulkarni GP, Chandrakantha T, Neha K. Second year medical student's feedback and perspective on teaching methodology in Pharmacology in a tertiary care teaching hospital from India. Sch. J. App. Med. Sci., 2016;4(6C):2089-94.

17. Sekhri K. Teaching methodologies in pharmacology: A survey of students perceptions and experiences. J Educ Ethics Dent. 2012;2:40-4.

18. Zaman SU, Beedimani RS, Pavani NT, Kumar KS. Feedback of second-year medical students' towards teaching/learning ofpharmacology in a private medical college of India. Int J Basic Clin Pharmacol 2016;5(5):2086-93.

19. Bandyopadhyay D. A Study On The Evaluation Of Perception Of Teaching-Learning Methods Of Pharmacology Among The 2nd M.B.B.S. Students In Burdwan Medical College, West Bengal, India. Reviews of Progress. 2012;1(12):1-11.

20. Desa SB, Keny MS. PowerPoint versus Chalkboard Based Lectures in Pharmacology: Evaluation of Their Impact on Medical Student's Knowledge and Their Preferences. Int J Adv Health Sci. 2014;1(5):10-4.

21. Seth V, Upadhyaya P, Ahmad M, Kumar V. Impact Of Various Lecture Delivery Methods In Pharmacology. EXCLI Journal. 2010;9:96-101.

22. Bhosale UA, Yegnanarayan R, Yadav GE. A Questionnaire Based Study to Evaluate Change in Attitude, Perception and Feedback of Second Year
Medical Students with Respect to Their Academic Terms on Teaching-Learning Methodology and Evaluation Methods in Pharmacology. National Journal of Laboratory Medicine. 2014;3(4):1-5.

23. Prasad SR, Kudthni RH, Santhosh R. A questionnaire based study of students' opinion on the teaching and learning methods in pharmacology in a medical school of India. Int $\mathrm{J}$ Basic Clin Pharmacol. 2016;5(6):2589-93.

24. Garg A, Rataboli PV, Muchandi K. Students opinion on the prevailing teaching methods in pharmacology and changes recommended. IJP. 2004;36:155-8.

25. Badyal DK, Desai C. Animal use in pharmacology education and research: The changing scenario. Indian J Pharmacol. 2014;46:257-65.

26. Sim SM. Teaching of pharmacology in University Malaya and the other medical schools in Malaysia: a historical perspective. Acta Pharmacological Sin. 2004;25:1209-19.

27. Shankar RP, Jha N, Bajracharya O, Shrestha R, Thapa HS. Teaching pharmacology at a Nepalese medical school: The student perspective. Australas Med J. 2010;1:14-22.

28. Medical Council of India. Minimum Standard Requirements for The Medical College For 150 Admissions Annually Regulations, 1999. Available from:

http://www.mciindia.org/helpdesk/how_to_start/STA NDARD\%20FOR\% 20150.pdf. Accessed on 15 March 2017.

29. Badyal DK, Bala S, Kathuria P. Student evaluation of teaching and assessment methods in pharmacology. Indian J Pharmacol. 2010;42:86-9.

30. Kamath A. A Review of Use of eLearning in Pharmacology. International Journal of Integrative Medical Sciences. 2015;2(9):157-62.

31. Khilnani G. Need for Restructuring Practical Pharmacology Undergraduate Curriculum. National Journal of Physiology, Pharmacy and Pharmacology. 2014;4(1):1-3.

Cite this article as: Vare VA, Kurle DG, Bagle TR, Hire RC, Shukla AO. Evaluation of teaching methods in pharmacology among MBBS students. Int J Basic Clin Pharmacol 2017;6:1352-7. 